\title{
Academician Sheindlin Turns 95
}

DOI: $10.1134 / \mathrm{S} 0018151 \mathrm{X} 11040183$

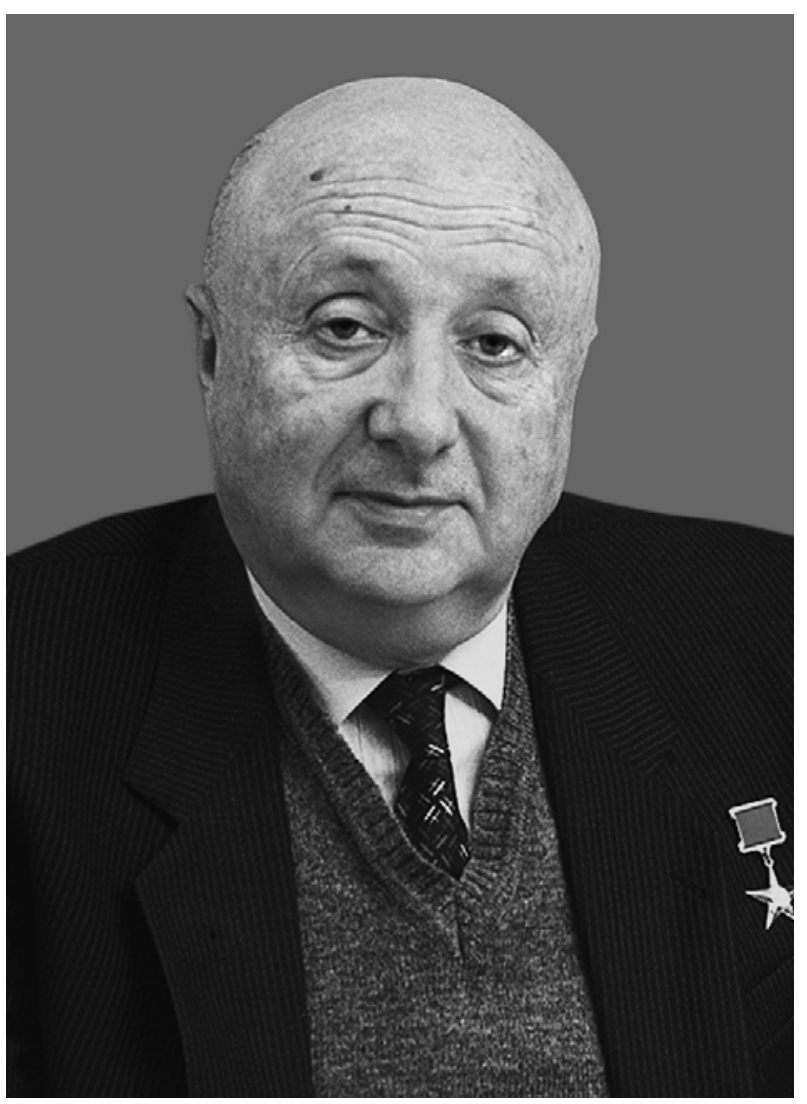

On September 4, 2011, the scientific community celebrated the 95th anniversary of the birth of Aleksandre Efimovich Sheindlin, an outstanding scientist and specialist in thermophysics and heat and power engineering.

Academician Sheindlin created the scientific basis for the modern thermal power industry, which provides $90 \%$ of all energy today. Professor Sheindlin performed pioneering research on the thermodynamic properties of water and steam, the basis for creating the new generation of thermal power stations with supercritical parameters. Many scientists carried out work in this field simultaneously with A.E. Sheindlin; however, it was he who managed to obtain the required solution. The results of his work have been introduced into all domestic and foreign reference books.

Many problems of the complex processing of solid organic fuel and obtainment of synthetic liquid and gaseous fuels, problems of the thermal impact on oil strata with a view to significantly increasing their heat emission were solved under the direction of Sheindlin.

Sheindlin was the founder of the Institute of High Temperatures and its permanent director for more than 25 years. Today he remains its director emeritus. $\mathrm{He}$ was the initiator of the foundation of the institute of High Energy Densities, as well as the Moscow International Energy Club, where he serves as vice-president. $\mathrm{He}$ is a member of the European Academy of Sciences and Arts, an honored member of the Hungarian Academy of Sciences and a number of other academies, and honored director of the Polytechnic Institute in Tampere (Finland) and Eindhoven University of Technology (the Netherlands).

Sheindlin is a Hero of Socialist Labor, winner of the Soviet Union State Prize, Lenin Prize, I.I. Polzunov Prize of the Russian Academy of Sciences, and the International Prize "Global Energy." He was a participant in the Great Patriotic War (WWII) and chevalier of two Lenin Orders, two Orders of the Red Banner of Labor, the Order of the Great Patriotic War, and Orders "For Service to the Motherland" of the 3rd and 2 nd degree. The international scientific community acknowledged the service of Academician Sheindlin by awarding him the Faraday Medal.

Aleksandre Efimovich was a founder of the journal Teplofizika Vysokikh Temperatur. He was its chief editor for more than 25 years, and he is still a member of its editorial board.

The editorial board and editorial staff of the journal congratulate Academician Sheindlin on the 95th anniversary of his birth with all their heart and wish him sound health and further success in his multifaceted activity. 